\title{
Insight into Gender Effect on EFL Writing Strategies in the Narrative and Expository Genres: A Case Study of Multilingual College Students in Morocco
}

\author{
Latifa El Mortaji ${ }^{1}$ \\ ${ }^{1}$ School of Humanities and Social Sciences, Al Akhaway University in Ifrane, Ifrane, Morocco \\ Correspondence: Latifa El Mortaji, School of Humanities and Social Sciences, Al Akhawayn University in Ifrane, \\ Ifrane 53000, Morocco. Tel: 212-6115-3944. E-mail: 1.elmortaji@aui.ma
}

Received: July 3, 2018

Accepted: September 5, 2018

Online Published: December 28, 2018

doi:10.5539/ies.v12n1p136

URL: https://doi.org/10.5539/ies.v12n1p136

\begin{abstract}
Research on gender and writing strategies in English as a foreign language (EFL) is scarce. This study investigates whether Moroccan male and female undergraduates use similar or different writing strategies when composing essays in the narrative and expository genres. Using think-aloud as a main research tool, a questionnaire, and retrospective interviews, the researcher collected data pertaining to male and female students' strategy use and cognitive processes while writing in EFL. The analysis of 64 think-aloud protocols revealed Moroccan undergraduates' use of a variety of writing strategies in terms of type and frequency. Both main types and subtypes of writing strategies emerged. Two-way Analysis of Variance (ANOVA) revealed that each gender group used some writing strategies more frequently than the other group; however, this difference in frequency of use was not statistically significant. In addition, the interaction of gender, writing strategy use, and discourse type yielded a significant difference in the use of the strategy of codeswitching only (i.e., language switch). On the other hand, the qualitative analysis of the protocols and interviews revealed a large variation between males and females in the use of the twelve strategies under investigation, together with overall writing behaviors. These strategies shall be presented together with recommendations for teaching composition in the EFL classroom.
\end{abstract}

Keywords: gender, writing strategy, narrative and expository genres, multilinguals, Moroccan EFL learners

\section{Introduction}

Writing is a complex and demanding task to both native and non-native speakers. Learning writing skills requires mastery in cognitive, social, cultural, and linguistic competencies (Ellis, 2015; de Oliveira \& Silva, 2016; di Gennaro, 2016; Mallia, 2017; Hussain, 2017). The writing skill is of paramount importance and one of the most essential skills required in college, as well as the workplace, to communicate knowledge (Wise, 2005). In fact, the ability to write clearly and concisely is seen as fundamental for effective and successful communication in both college and workplace situations.

In the 1960's, the main focus of researchers and teachers of English composition was on the final product (i.e., essay), in belief that spelling and grammatical accuracy were the key to effective writing. At that time, writing was viewed as a linear activity. In the 1970s and 1980s there was a major paradigm shift from the traditional product oriented approach to the process one. This change made it possible for composition teachers and researchers to have a better understanding of the complex nature of the composing process. Using think-aloud procedure, observation, and retrospective interviews, which were audio or video recorded, researchers could identify and describe the cognitive and metacognitive aspects of the writing process, together with the writing strategies involved. The major findings of these studies marked a turning point in the way writing was perceived and taught, and contributed to developing different composing process models (Emig, 1971; Perl, 1981; Hayes \& Flower, 1983).

Subsequent research revealed that effective writing involved the use of some major strategies, such as drafting, planning, generating ideas, and revising (Blanton et al., 2002; Hyland, 2002). Much of this research was conducted in the first language (L1), and then similar research and methodology were applied to English as second or foreign language (ESL/EFL), in order to explore and study transfer of writing habits, skills, knowledge, and strategies from one language to another. For example, early research in L1 and L2 reported similarities in the L1 and L2 
writing processes of proficient writers (Pianko, 1979; Sommer, 1980; Zamel, 1983). Indeed, these proficient writers approached their writing experience as a process of "creating and discovering meaning" (i.e., text). In other words, the writers used a set of strategies to brainstorm, find ideas, evaluate them, plan how to proceed, then commit their ideas to paper, then read text produced so far with the purpose of discovering and brainstorming more ideas to develop, then reread with the purpose of evaluating and revising the text produced so far, then move on to the next paragraph, and so on. These strategies were used recursively with the purpose of moving forward and producing more text (Zamel, 1983, p. 207). These writing behaviours clearly showed that proficient writers did not write in a linear manner, and used a number of strategies frequently and repeatedly at different levels of the writing process, which did contribute to the recursive nature of the whole process. In addition to these main strategies, more subtypes were identified to further explain the complexity of the writing process and students' writing behaviours. For instance, the main strategy of reading involved many sub-types, like reading the prompt (Rpr), reading key words in the assigned topic (Rkw), reading text committed to paper so far (Rtsf), reading the title (Rt), reading the fourth sentence (RS4), reading the second paragraph (RP2), and so on.

While investigating learners' writing processes, researchers looked at some variables in relation to writing strategy use, such as age, proficiency, social class, L1 and L2 interference, and rhetorical genres involved. However, the interaction between gender and writing strategy use was investigated in L1 only. Indeed, this variable of gender was overlooked in English as a second or a foreign language. As a matter of fact, many researchers have made serious recommendations to (a) conduct more studies investigating students' writing strategy use in interaction with gender (Khalil, 2005; Mallia, 2017; Hussain, 2017; Mutar \& Nimehchisalem, 2017), and (b) use complementary data collection like think-aloud protocols and interviews (Khalil, 2005, p. 113). Thus, the present study intends to fill in this gap by studying the cognitive processes and writing strategies used by male and female multilinguals writing academic essays in the narrative and expository genres in English as a foreign language. Our aim is to (i) explore the set of writing strategies used, then (ii) investigate to what extent males and females use similar or different strategies across different writing tasks, and (iii) see if there is any specific pattern or behaviour(s) that distinguishes one group from the other. The strategies we shall be concerned with are: Planning, Reading, Rehearsing, Revising, Assessing, Translating, Awareness, Codeswitching, Commenting, Editing, Metacommenting, and Questioning.

\section{Literature Review}

According to the literature, very few studies were conducted on gender and ESL/EFL writing strategy use. Most research involving gender as a variable investigated language learning strategies in general and not specifically writing strategies. In her study on individual differences and writing ability, Ong (2015) reported that Sunderland (2000) "identified gender as an extremely neglected factor in second language writing" (p. 129). The few existing published studies reported on male and female students' writing strategies in terms of the frequency of their occurrence (Mutar \& Nimehchisalem, 2017; Bremner, 1999; Guobing, 2015), and the interaction of writing proficiency level and gender in overall language learning (Khalil, 2005).

Khalil (2005) studied the effect of language proficiency and gender on Palestinian EFL learners' strategy use. Using Oxford's (1990) questionnaire known as Strategy Inventory for Language Learning (SILL), the researcher collected data from both high schoolers and university students. The findings show that proficiency level and gender have a main effect on the students' overall strategy use, and not on the use of specific individual strategy or category of strategies. The most frequently used writing strategies by University students were metacognitive and social strategies like planning. As for gender effect, ANOVA revealed significant females' use of metacognitive (i.e. planning and evaluation of learning) and memory (i.e. remembering and retrieving information) strategies. Compared to proficiency level, the variable of "gender has a main effect on only two categories, namely memory and metacognitive, in favour of females" (p. 113). Unlike the current study, Khalil investigated students' learning strategies in general and not specifically writing strategies. In addition, data was collected using a SILL questionnaire, while this study collected complementary data using retrospective interviews and think-aloud protocols that tap directly into the students' cognitive processes.

Guobing (2015) investigated Chinese senior high school students' writing strategy use in interaction with gender and proficiency level using a "Chinese writing strategies questionnaire". One-way ANOVA was performed to investigate possible differences between males and females. The researcher reported a significant difference within the male and female groups. Female students used writing strategies better, and their general strategies and writing habits were different from the ones used by male students. "Female student writers received significantly higher writing strategy employment scores than that of male students" (p. 847). In addition, the writing competency test revealed that female students were more influenced by their first language (L1) since they used 'coinage' to invent words when they did not know suitable words in the target language. The questionnaire shows that while females 
had negative transfer from L1, male students displayed a more positive transfer from their mother tongue.

In a recent study, Mutar and Nimehchisalem (2017) investigated the effect of gender and proficiency on writing strategy use among Iraqi high schoolers. Using a writing strategy survey adapted from Petric and Czarl (2003, as cited in Mutar \& Nimehchisalem, 2017), they found no significant difference between high and low proficiency students' strategy use. However, females used more strategies than the males. The researchers identified three groups of strategies: pre-writing, while writing, and revising strategies. The most commonly used strategies by participants were writing and revising strategies. In fact, "the pre-writing strategies were far less frequent than the other strategies. Thus, the participants are categorized as low strategy users across all writing strategies types" (p. 176). They used their strategies "in a very similar way". As for proficiency level effect on students' writing strategy use, no significant differences were found between high and low proficiency students. However, as far as gender is concerned, "based on the results of independent samples t-test, there is a significant difference between female and male students' strategy use" (p. 177).

As illustrated in the literature review, in addition to the limited number of studies investigating gender and writing strategy use in English as second/foreign language, no studies investigated ESL gender in correlation with writing strategy use and discourse type. Furthermore, while all these studies investigated strategy use in English as a second language, the subjects involved in the current study are multilinguals having access to four or five languages, and English is their fourth language. Finally, while all these studies were based mainly on questionnaires, in this study we used three tools, namely think-aloud protocols, interviews, and a questionnaire as recommended by previous researchers. Thus, this study intends to fill in this gap and investigate the effect of gender and type of discourse on students' writing strategy use when writing in English as a foreign language.

\section{Research Questions}

The aim of this study is threefold. We shall try to answer the following questions:

RQ1. What types of writing strategies do Moroccan EFL learners use when writing in English?

RQ2. Is there a significant difference between males and females in their writing strategy use?

RQ3. Is there a significant difference between the correlation of gender, discourse genre, and writing strategy use?

\section{Methodology}

\subsection{Participants}

Twenty (20) freshmen Moroccan university students aged 17 to 19 participated in the study, including ten females and ten males. The students were enrolled in an English composition course whereby they had received formal instruction in academic essay writing in the narrative and expository genres. In that course the participants were introduced to the five-paragraph essay and academic essay writing techniques, including purpose and audience specification, coherence and unity, organization, and appropriate grammar use. In addition to English composition, they were introduced to guided-reading whereby they produced pieces of writing in response to short stories and novels. The participants represented a homogeneous group because they were all freshmen and they were exposed to academic English instruction in the classroom as a foreign language for approximately the same number of years. In addition, all participants had access to four languages: Moroccan Arabic (L1), Modern Standard Arabic (L2), French (L3), and English (L4).

\subsection{Procedure and Instruments}

The researcher met with the participating students and explained to them the purpose of the research and what it involved. Once the consent forms signed, a questionnaire was administered in the first week to gather demographic data about the subjects. Then, individual meetings were scheduled in the second week to provide the participants with practice in "think-aloud" through verbalizing their thoughts and what was going on their minds while they were involved in the writing process of their essay. Both introspective (during writing) and retrospective (right after writing) methods were introduced. After the think-aloud training, the researcher met with the participants for four sessions each, spread over eight weeks, from week 3 to week 10, to collect recorded think-loud data from the students while writing essays in response to four topics in the narrative and expository genres. Once the researcher transcribed and coded data (see data collection section 4.3.), she examined the students' protocols carefully and scheduled individual interview sessions in the subsequent week to collect further material on the students' writing strategies they used in the protocols.

\subsection{Data Collection}

Data was collected over a period of eleven weeks using three methods. The demographic questionnaire was administered at the beginning of the research to collect personal information about the students, namely their age, 
gender, year of study, the formal writing instruction they had received at the university, specific writing courses, and the number of years they had been learning English as a second foreign language. The participants' think-aloud protocols were audio-taped, transcribed, and coded using an adapted reviewed version of Perl's coding scheme (1981). An excerpt of a student's coded protocol is presented in table 1. Two experienced coders (A and B) helped the researcher transcribe the protocols. The coding scheme interrater reliability check was high in this study and consistent with previous studies. In fact, for the researcher and coder A and the researcher and coder B it was $86 \%$ in the main strategies (MS) and $77 \%$ in the subtypes (SB), and $94 \%$ in MS and $83 \%$ in SB, respectively. Finally, individual interview sessions were conducted to collect more information and explanation about the actual writing strategies used by the participants, as identified and coded in the protocol analysis.

Table 1. Sample of a student's think-aloud protocol

\begin{tabular}{|c|c|}
\hline Student & Excerpt of student Think-Aloud Protocol \\
\hline $\mathrm{S} 12$ & 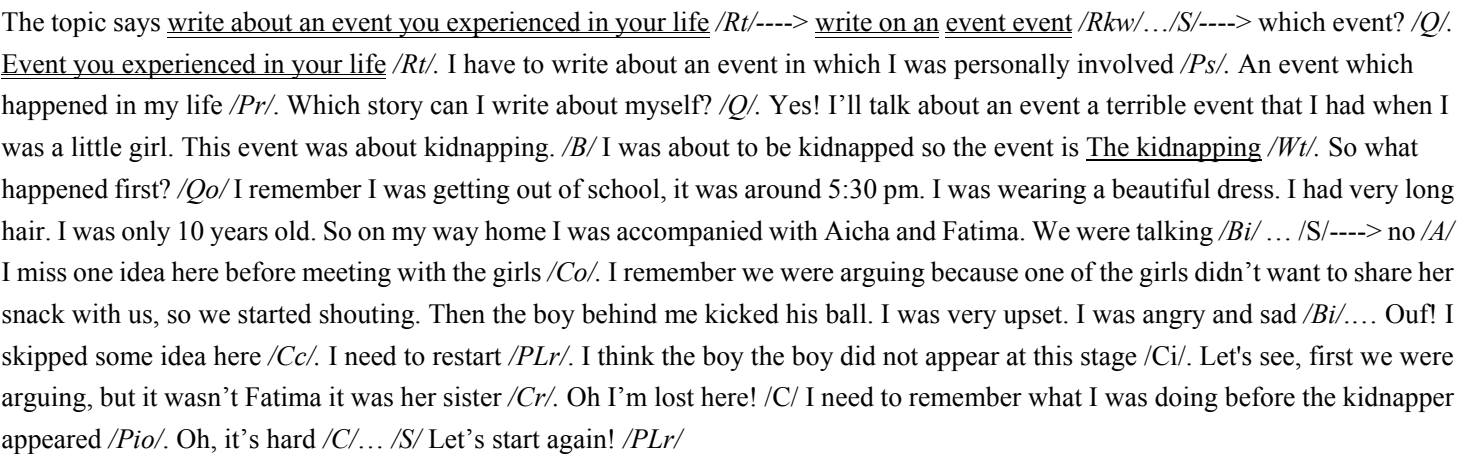 \\
\hline
\end{tabular}

Note. Double underlined words are text being read; single underlined words are text being written down; non-underlined words refer to externalized thoughts using think-aloud procedure; / / refer to coded writing strategies.

\section{Analysis}

Collected data were analysed quantitatively and qualitatively. Given that four students did not finish their writing tasks, the analysis reports on sixteen students only. To carry out the statistical tests, the Analysis of Variance (ANOVA) procedure within the Statistical Package for the Social Sciences (SPSS) for Windows was used. To test main effects and selected interaction effects on use of each writing strategy separately, two way ANOVAs were used. The dependent variables were the frequencies of occurrence of each of the main twelve writing strategies for each writer. ANOVA was used for writing strategy frequency counts and correlation between writing strategies, gender, and discourse. For differences in each strategy to be statistically significant, its $p$ value has to be $p<.05$. For the qualitative analysis, the students' think-aloud protocols were coded and examined carefully for further explanation and evidence in support of students' composing behaviours, to see whether there were any patterns, approaches, and writing strategies which clearly distinguished between males and females across the writing tasks.

\section{Results}

\subsection{Overall Strategies Used}

This section answers Research Question \#1: What types of writing strategies do Moroccan EFL learners use when writing in English?

Descriptive statistics for the types and overall frequency of use of writing strategies revealed that Moroccan students used twelve main types of writing strategies: Planning, rehearsing, reading, assessing, awareness, revising, editing, codeswitching, translating, commenting, meta-commenting, and questioning. The overall total of these strategies across the four writing tasks is 5139 . The frequency of occurrence per strategy for each individual participant ranged between 102 and 961 . Therefore, the average frequency was 80.3 strategy occurrence per writer per composition. Table 2 presents the frequency distribution of the writing strategies per subject. 
Table 2. Frequency distribution of the writing strategies

\begin{tabular}{cccccccccccccc}
\hline Subject & Ass & Awa & Com & Cds & Edt & Mcm & Pln & Qst & Red & Reh & Rev & Trs & Total \\
\hline S1 & 1 & 2 & 3 & 6 & 0 & 0 & 14 & 4 & 29 & 17 & 21 & 5 & 102 \\
S2 & 21 & 2 & 7 & 108 & 1 & 1 & 30 & 9 & 98 & 64 & 33 & 4 & 378 \\
S3 & 7 & 0 & 2 & 7 & 1 & 0 & 7 & 0 & 143 & 10 & 22 & 0 & 199 \\
S4 & 6 & 1 & 1 & 5 & 3 & 0 & 3 & 0 & 46 & 19 & 18 & 0 & 102 \\
S5 & 9 & 0 & 2 & 11 & 3 & 0 & 4 & 1 & 114 & 50 & 35 & 2 & 231 \\
S6 & 10 & 3 & 9 & 2 & 4 & 1 & 20 & 4 & 43 & 30 & 10 & 8 & 144 \\
S7 & 19 & 3 & 7 & 13 & 7 & 0 & 17 & 0 & 30 & 91 & 37 & 3 & 227 \\
S8 & 18 & 4 & 1 & 3 & 8 & 0 & 10 & 2 & 92 & 15 & 44 & 5 & 202 \\
S9 & 20 & 0 & 2 & 4 & 9 & 0 & 4 & 3 & 123 & 39 & 34 & 5 & 243 \\
S10 & 2 & 0 & 0 & 0 & 10 & 0 & 5 & 0 & 74 & 7 & 41 & 0 & 139 \\
S11 & 16 & 6 & 3 & 1 & 12 & 0 & 20 & 0 & 64 & 45 & 62 & 0 & 229 \\
S12 & 55 & 6 & 8 & 21 & 16 & 3 & 46 & 4 & 246 & 190 & 128 & 13 & 736 \\
S13 & 20 & 1 & 2 & 1 & 22 & 0 & 29 & 1 & 198 & 64 & 123 & 1 & 462 \\
S14 & 6 & 3 & 3 & 4 & 26 & 2 & 15 & 0 & 85 & 97 & 60 & 21 & 322 \\
S15 & 12 & 31 & 19 & 0 & 27 & 0 & 128 & 1 & 81 & 104 & 59 & 0 & 462 \\
S16 & 39 & 43 & 16 & 28 & 50 & 9 & 91 & 4 & 135 & 485 & 50 & 11 & 961 \\
Total & 261 & 105 & 85 & 214 & 199 & 16 & 443 & 33 & 1601 & 1327 & 777 & 78 & 5139 \\
\hline
\end{tabular}

As illustrated, student S16 used more writing strategies than his counterparts (961). The second and third highest strategy occurrence was used by students S12, followed by S13 and S15 who used a total of 736 and 462 strategies, respectively. The sixteen participants used 'reading' (1601 times), rehearsing (1327), revising (777) and planning (443 times) repeatedly and recursively. As for the mean frequencies of use of these writing strategies, they are, respectively, 100, 83, 49, and 28. On the other hand, the least used strategies were meta-commenting [16 times, mean 2], questioning [33, mean 3], translating [78, mean 5], and finally commenting [85, mean 5].

The qualitative analysis of the think-aloud protocols revealed that Moroccan student writers did a great deal of metacognitive processing that falls in Hayes and Flower's central boxes of the writing process model (1983), namely the planning/rehearsing box and reading/revising box. Furthermore, most students used these writing strategies recursively throughout the writing process. Also, the students' higher use of revising (i.e., which relates to the meaning/ content) than editing (i.e., which relates to the formal aspect of their writing) suggests that the participants did not behave like beginner or basic writers who usually focus on low level improvement; rather, they paid considerable attention to the message they were trying to communicate to the audience.

\subsection{Gender Differences in the Frequency of Use of Writing Strategies}

This section answers Research Question \#2: Is there a significant difference between males and females in their writing strategy use?

The hypothesis formulated here is that there would be no significant differences between females and their male counterparts in the frequency of use of writing strategies. 


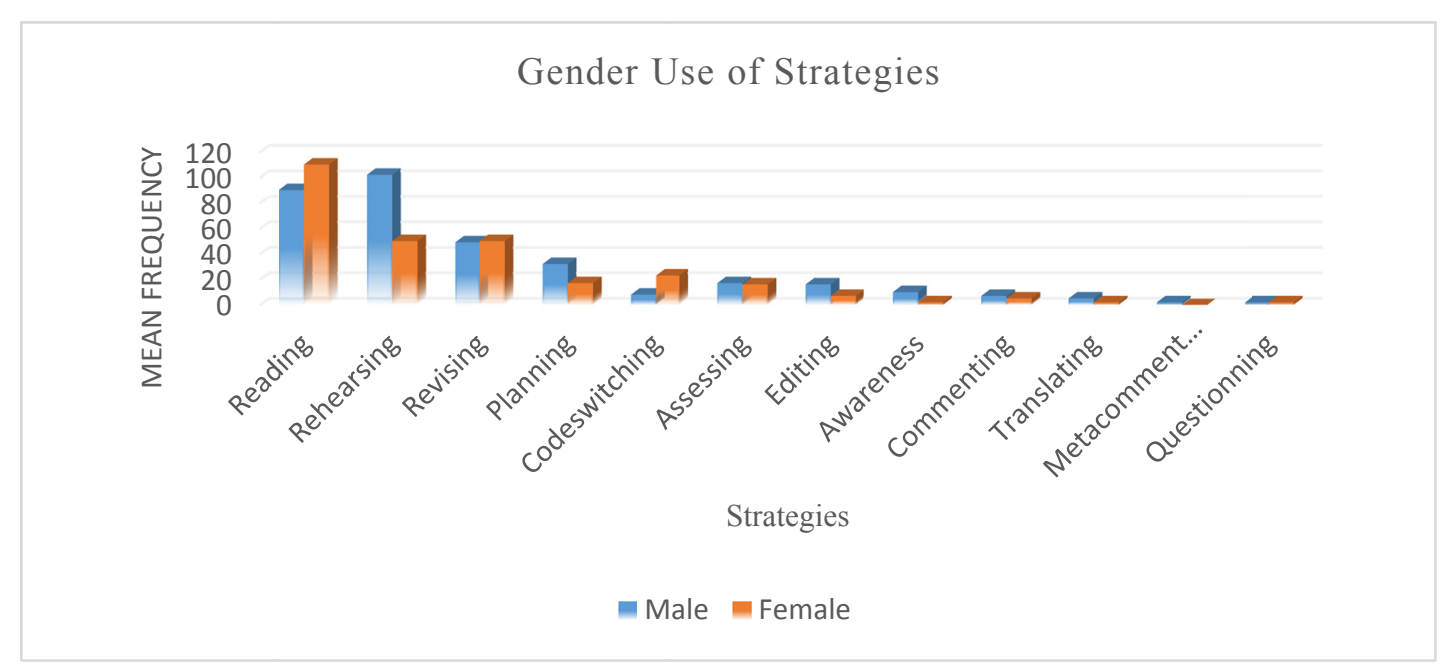

Figure 1. Strategy use by males versus females

Figure 1 indicates that male students used seven writing strategies twice as frequently as did the females, namely awareness, commenting, meta-commenting, editing, planning, rehearsing and translating. The female subjects, however, used reading slightly more frequently and code-switching three times more frequently than the males. Despite these frequency differences, statistical analysis revealed no significant differences between male and female students in the frequency of use of writing strategies. Hence, the null hypothesis is largely confirmed.

According to ANOVA results for the gender main effect on the frequency of use of writing strategies, the only strategy which is almost significant is reading $[\mathrm{F}=4.54$, sig. of $\mathrm{F}=.051 ; \mathrm{p}<.05]$, but again this result is border line. The reason why there are no significant differences between males and females in the frequency of use of writing strategies is that the same variation in strategy use was observed within both groups, such as reading, assessing, and meta-commenting.

The qualitative analysis of the protocols revealed that almost all writers in both the female and male groups approached their tasks at the beginning of the writing process in almost the same way (i.e., paraphrasing topic, underlining key words) and used the same set of strategies like reading, planning, rehearsing, revising and editing. However, differences were mostly noted in the frequency and subtypes of these main strategies. For instance, in the case of planning, while some students used this strategy at local and global levels, including planning the type of story to narrate, planning the content of paragraphs, planning to bring an idea to end, and planning idea and paragraph organisation, other students used the strategy of planning mostly at a global level with a limited number of subtypes. This variation of strategy use occurred among males and females. Therefore, some students used the identified strategies more frequently and more effectively than others, regardless of gender. In addition, the qualitative analysis of the think-aloud protocols clearly showed that some male students were better verbalisers than others, and spent more time than others planning, rehearsing, assessing their brainstormed ideas, and editing written text at different levels of the writing process, which caused some variation within the male group. The same variation was observed amongst the females; some tended to read the assigned topics (i.e., prompt) and text in progress, using comments every now and then in a different language (i.e., French) at many levels of the writing process, while others used these strategies less often. Hence, the quality of these strategies differed from one writer to another within each group. This variation within the male and female groups, respectively, explains and supports the statistical result about the non-significance of these differences. In other words, there was no clear pattern that clearly distinguished males as a group and females as a group in their writing strategy use.

Having said this, it is worth mentioning that the majority of females used the strategy of planning more strategically than the males. Using their prior knowledge about the narrative writing techniques learnt in previous courses, they retrieved schema and formal schemata from their long term memory (LTM) in order to make local and global planning. The retrieved information related to the audience, purpose, the structure, organization, narrative techniques, word choice, tense, and so on. On the other hand, the males retrieved very little information about essay writing in the narrative genre. Their planning was mostly global and sometimes done at a superficial level, and in some cases it did not help much with idea generation and paragraph development. Therefore, most female students used their past reading and writing experiences, which enabled them to use their writing strategies more effectively than their male counterparts. 
Another main difference between the males and females was flexibility. While female students repeatedly changed their pre-planned ideas, paragraph organization, and even sentences when they explored new ideas or a better organization of their text in progress, most male students tended to keep their original plans. The males' main concern was to finish their idea or story development, while the females were more 'perfectionist' and considered their audience's expectations and needs at different levels of the writing process. This explains the females' excessive use of reading, together with questioning and assessment strategies in French language, compared to their male counterparts. The females' ability to set problems and goals and make decisions based on their audience awareness did eventually contribute to the good quality of their final essays.

\subsection{Interaction of Gender with Discourse Type in the Writing Strategies Used}

This section answers Research Question \#3: Is there a significant difference between the correlation of gender, discourse genre, and writing strategy use?

ANOVA results yielded a significant gender by discourse type interaction effect on the frequency of use of code-switching only $[\mathrm{F}(1,15)=6.13, \mathrm{p}=.027 ; \mathrm{p}<.05]$. Females used code-switching more frequently than males. This high frequency in the female group was found in the expository genre, unlike the males (see table 3). In addition, while the male group was homogeneous, there was more variation between females in switching from one language to another.

Table 3. Gender by discourse type effect on the use of codeswitching

\begin{tabular}{cccccc}
\hline & \multicolumn{3}{c}{ Expository } & \multicolumn{2}{c}{ Narrative } \\
\hline Gender & Number & Mean & Std. Dev. & Mean & Std. Dev. \\
Female & 10 & 14 & 24 & 10 & 18 \\
Male & 6 & 4 & 2.5 & 6 & 3.75 \\
\hline
\end{tabular}

The qualitative analysis of the protocols revealed that almost all females switched to French while writing their expository essay in English. These switches consisted of long chunks such as sentences and paragraphs. In addition, they occurred at different levels of the writing process and in conjunction with strategies like rehearsing, assessing, commenting, and planning. On the other hand, males rarely switched, and when they did it was in Arabic. Also, the quality of the males' switches differed and consisted of smaller units such as words. Another difference is the large variation amongst the females themselves in code-switching, while the males' group is more homogeneous. The noted variation between the females is explained by subject S2 who excessively switched from one code to another compared to other females. The strategy occurred 108 times in total, including 63 times in expository and 45 times in the narrative genre. The analysis of the questionnaire and the interview revealed that the reason for this high frequency is her French educational background. Indeed, attending 'la mission Française' in primary school explains her tendency to speak as much French as possible at different levels of the cognitive process of writing in English. Her preference for French was also observed in the interview since she was the only participant who requested to answer all interview questions in French.

In addition to the variation of using codeswitching across gender and writing tasks, the qualitative analysis of the protocols demonstrated that the overall writing process in the expository discourse was more straightforward than the narrative one. Although at a first glance the writers seemed to use the same approach and pattern of reading assigned topics, rereading key words, rehearsing, planning at local and global levels, outlining, revising, and editing, most students used less interruptions between sentences and main ideas in the expository genre. They made more repeated stops in the narrative writing process because they presented to themselves more problems to solve in the narrative task. For example, they needed to decide on a happy or sad story, true or imagined event, the number of characters, the setting, and so on. In fact, the writers brought up their prior knowledge from courses, like English composition and guided-reading, to plan the content, structure and organization of their narrative essay (i.e., before, during, and after the climax), while in the expository they briefly referred to basic essay writing techniques (i.e., introduction, body, conclusion, definition, hook). According to the interviews, the students found the narrative task more demanding than the expository, which clearly supports these findings.

\section{Discussion}

This study has examined the effect of gender on multilingual Moroccan EFL students' writing strategies in the narrative and expository genres. Using think-aloud procedure, interviews, and a background questionnaire, the protocols revealed the occurrence of twelve main strategies that the students used recursively throughout the writing process, and the positive association between past reading and writing experiences received in previous 
courses and effective strategy use. Descriptive statistics demonstrated that the most commonly used strategies were reading, followed by rehearsing, revising and planning. The students' use of these strategies repeatedly and recursively shows that the writers gave priority to high level concerns (i.e., ideas, content, message) and addressed low level concerns, (i.e., form, grammar, spelling) at a later stage. This clearly indicates that the students behaved like non-basic writers.

As for gender differences in writing strategy use, statistical analysis showed that the males used seven writing strategies twice more than their female counterparts, while females used two strategies more frequently than male students. However, although there seemed to be differences and variance in terms of the frequency of occurrence of these strategies within the male and female groups, none of these differences were found statistically significant. This was due to variation in strategy use that was found within both female and male groups. However, the qualitative analysis revealed interesting gender differences in writing behaviours and strategy use. Indeed, the protocol analysis clearly illustrated that most females heavily relied on their Long Term Memory to retrieve prior reading and writing experiences acquired in English composition and guided reading courses. This behaviour helped the females to use better and more planning strategies than the males in terms of types, frequency, and effectiveness. This was particularly true in the narrative task whereby most females excelled in paragraph organization and their writing style. Finally, the protocol analysis revealed that the writing process was more straightforward in the expository genre than the narrative one, because, and as confirmed by the interviews, the students found the narrative more demanding and therefore needed to present more problems to themselves to solve. This explains the higher number of strategy subtypes used and the great recursiveness observed in the narrative genre. Similar findings were achieved in some previous research which reported that female and male writers differed in their writing strategy use and habits, together with the females' ability to follow the teacher's guidelines, which contributed to the females' use of more effective strategies and "much higher language proficiency", and eventually contributed to the females' "higher score" compared to the males (Guobing, 2015, p. 847).

Regarding the correlation between discourse types and gender, a two-way ANOVA was used for further analysis. Results revealed codeswitching as the only strategy that was statistically significant in correlation with gender and discourse type. Females used codeswitching more frequently than males who rarely switched from one code to another. This finding is consistent with previous research like Guobing (2015) and Mutar \& Nimehchisalem (2017) who found significant differences in the females' use of certain strategies compared to male students. In addition, females used codeswitching more frequently in the expository than the narrative genre, while male subjects used codeswitching more in the narrative. Furthermore, more variation was noted within the female group, while the male group was homogeneous in the use of codeswitching. The interview revealed new variables explaining this variation, mainly some female student's educational background that did contribute to the high frequency of switching from English to French while writing in English. Guobing (2015) reported females' heavy reliance on their first language when they encountered linguistic difficulties. This switch resulted in 'coinage', which involved "inventing new words". In the current study language switch served the users to make comments and ask questions.

\section{Recommendations for Teaching EFL Composition}

Based on the discussion above, our recommendations for teaching English Composition to EFL learners are as follows:

- The writing process of the expository genre proved to be straightforward compared to the narrative. Thus, there is a need to teach students to use more strategies in the expository discourse.

- The narrative discourse is more demanding than the expository, so the expository should be taught first to ensure students learn the necessary strategies.

- Female students used subtypes of main strategies effectively, while the males limited themselves to main strategies only. Therefore, males need to be encouraged to explore and use a variety of subtypes of writing strategies through well-crafted short writing exercises with specific goals.

- Prior knowledge proved to have an effective impact on females' strategy use and the quality of their final narrative essays. On the other hand, male students did not retrieve their previous writing and reading experiences from their long term memory, and were therefore not personally involved in their writing. We recommend exposing male students to more personal narrative topics, and using more strategies pertaining to purpose and audience specification.

- Using the strategy of codeswitching helped the students to make comments about their feelings and 
psychological state during the writing process, and ask questions about generated ideas and text in progress. Since this strategy was not a hindrance to the writing process, multilingual students should be encouraged to brainstorm, plan and evaluate in any language they feel comfortable with.

\section{Conclusions}

In this study, the quantitative and qualitative data analysis revealed interesting results and findings. (a). Moroccan undergraduates used a set of twelve major writing strategies recursively during the writing process of composing essays in English as a second foreign language, though overall some strategies were more frequently used than others. (b). Male students used seven writing strategies more frequently than female students, and the latter used two main strategies more frequently than their male counterparts, but this difference was not statistically significant. This was due to 'variation' in strategy use that was found within both female and male groups. (c). Interaction between gender and discourse type revealed that the writing process in the expository discourse was more straightforward than in the narrative. (d). The majority of females retrieved from their LTM information based on their past formal reading and writing experiences, which explains their effective strategy use in the narrative. (e). Interaction between gender, discourse type, and writing strategies yielded a significant difference in the use of codeswitching as a writing strategy. The qualitative analysis of the protocols revealed that both males and females differed in the quality of their codeswitching: (i) while the females used long chunks, such as group of sentences and paragraphs, male students used small units like words and single sentences. (ii) Female students code-switched more in the expository genre, while male students code-switched mainly in the narrative. (iii) Language switch served the users to make comments and ask questions, and helped the students move forward in the writing process. (iv) The male group was homogeneous compared to the female group where more variation was observed in this strategy use. (v) Some males codeswitched mainly from English to Arabic, while females codeswitched back and forth from English to French. The questionnaire and the interview revealed the 'educational background' as an important variable responsible for some students' excessive use of French, which explained the variation observed in the female group as this variable concerned specific students only. These differences in strategy use, prompted both general and gender-specific recommendations for the teaching of EFL composition.

\section{References}

Blanton, L. L., Kroll, B., Cumming, A. H., Erickson, M., Johns, A., Leki, I., \& Silva, T. (2002). ESL composition tales: Reflections on teaching. Ann Arbor: University of Michigan Press. https://doi.org/10.3998/mpub.8800

Bremner, S. (2009). Language Learning strategies and language proficiency: investigating the relationships in Hong Kong. Canadian Modern Language Review, 55, 490-515. https://doi.org/10.3138/cmlr.55.4.490

De Oliveira, L. C., \& Silva, T. (2016). Second Language Writing in Elementary Classrooms: An Overview of Issues. In Second Language Writing in Elementary Classrooms (pp. 1-10). Palgrave Macmillan UK. https://doi.org/10.1057/9781137530981_1

Di Gennaro, K. (2016). Searching for differences and discovering similarities: Why international and resident second- language learners' grammatical errors cannot serve as a proxy for placement into writing courses. Assessing Writing, 29, 1-14. https://doi.org/10.1016/j.asw.2016.05.001

Ellis, R. (2015). Understanding Second Language Acquisition (2nd ed.). Applied Linguistics. Oxford University Press.

Emig, J. (1971). The composing processes of twelfth-graders. NCTE Research Report \#13, National Council of Teachers of English: Urbana, Illinois.

Guobing, L. (2015). Investigating the English Writing Strategies Used by Chinese Senior High School Students. Theory and Practice in Language Studies, 5(4), 844-850. https://doi.org/10.17507/tpls.0504.21

Hayes, J. R., \& Flower, L. S. (1983). "Uncovering cognitive writing processes: An introduction to protocol analysis". In P. Mozenthal, C. Tamor, \& S. A. Walmsley (Eds.), Research in Writing: Principles and Methods (pp. 207-220). New York: Longman

Hussain, S. S. (2017). Teaching Writing to Second Language Learners: Bench-marking Strategies for Classroom. Arab World English Journal, 8(2). https://doi.org/10.24093/awej/vol8no2.15

Hyland, K. (2002). Teaching and researching writing. New York: Longman.

Khalil, A. (2005). Assessment of Language Learning Strategies Used by Palestinian EFL Learners. Foreign Language Annals, 38(1), 108-119. https://doi.org/10.1111/j.1944-9720.2005.tb02458.x 
Mallia, J. (2017). Strategies for Developing English Academic Writing Skills. Arab World English Journal (AWEJ), 8(2), 3-15. https://doi.org/10.24093/awej/vol8no2.1

Mutar, Q. M., \& Nimehchisalem, V. (2017). The effect of Gender and Poficiency Level. Arab World English Journal (AWEJ), 8(2), 171-182. https://doi.org/10.24093/awej/vol8no2.12

Ong, J. (2015). Do individual differences matter to learners' writing ability? The Asian Journal of Applied Linguistics, 2(2), 129-139. Retrieved from http://caes.hku.hk/ajal

Perl, S. (1981). Coding the composing process: A Guide for Teaches and Researchers. Manuscript written for the National Council of Education, Washington D.C.

Pianko, S. (1979). A description of the composing processes of college freshman writers. Research in the Teaching of English, 13(1), 5-22.

Sommer, N. (1980). Revision strategies of student writers and experienced adult writers. College Composition and Composition, 31(4), 378-388. https://doi.org/10.2307/356588

Wise, K. (2005). The Importance of Writing Skills. Public Relations Quarterly. Rhinebeck, 50(2), 37-40, 48.

Zamel, V. (1983). The composing processes of advanced ESL students: Six case studies. TESOL Quarterly, 17 , 165-187. https://doi.org/10.2307/3586647

\section{Copyrights}

Copyright for this article is retained by the author(s), with first publication rights granted to the journal.

This is an open-access article distributed under the terms and conditions of the Creative Commons Attribution license (http://creativecommons.org/licenses/by/4.0/). 